\title{
The Research on The Present Situation and Countermeasures of the Lack of Honesty for College Students
}

\author{
Guofeng Zhao \\ Ideological and political Teaching, XiJing University, shaanxi ,710123,china.
}

Keywords: College Students; Honesty; Status qua; Countermeasures

\begin{abstract}
Taking the college students as the object of study, this paper analyzes the phenomenon of dishonesty in the university campus, and the honesty and credit are seriously absent, and the honesty of university students is also facing a crisis. It points out that the society, schools, families as well as students themselves are the key to strengthen the hon esty education of university students. To enhance the college students' honesty status must be necessary honesty education of college students, it is also needed to improve the current credit mechanism etc..
\end{abstract}

\section{Introduction}

Honesty is the traditional virtue of Chinese culture. Promoting honesty and integrity of the moral level is important for the entire nation and promoting social stability and other aspects is of a very important significance. As builders and successors of the cause of socialism, contemporary college students are directly related to the stability and development of our socialist cause.

\section{Significance of college students honesty}

Honesty is the traditional virtue of Chinese culture, and the moral norm that all human beings agree with. Promoting honesty of the ethical level is as important as to promote economic progress for the whole society, , in line with the development of advanced productive forces, social stability and other aspects of great significance. As the contemporary college students represent the future builders and successors of the country, their honesty situation will directly relate to the socialist modernization of our country smoothly. As the important part for the future development of society, college students with no credibility will slow the pace of the development of productive forces which is the destruction of productivity; honesty is the essence of traditional culture, is also the important content of advanced culture, if college students on China's traditional virtue do not inheritance to the traditional culture, they will lose the social culture, which makes the moral cognition level decreased, and be more contrary to the direction of advanced culture. Integrity reflects the fundamental interests of the overwhelming majority of Chinese people and the people of China training students to become useful persons, college students should be the ones with grateful heart to repay the society, otherwise, they will seriously damage people's interests.

Honesty is the pre requisite and basis for college students to succeed in career. College students are the hope of social progress, the vigorous development of a market economy requires contemporary college students to master certain professional knowledge. They must in the field of ethics and moral areas continue to improve themselves. In economic society, favor has both ability and political integrity to the society, talent without virtue or Youde does not only to gain a foothold in the society. Integ rity is the conduct of contemporary college students and is the comerstone of the college students' interpersonal communication, which is essential for healthy personality of college students, and for guarantee for the college students to realize self value.

Honesty is the essential content of the college students' comprehensive development. Implementation of civic moral construction program for the integrity of the Chinese citizens of the twenty basic moral code, this specification has aroused strong repercussions in the country. For college 
students, personal credit first embodies to abide by the principle of good faith spirit of reverence. Taking the honesty and credit as the basis of founding of the shelter, regardless of work or study, do erudite, down-to-earth, bears the burden of responsibility; establish es facts, credible, and cannot stand the idea of develop quality, consistent behavior.

Honesty is the key key to college students. In contemporary society, people increasingly take the quality of honesty and credit. College students in school study are in a transitory stage of the process, and eventually they have to go into the community and the market. In the upcoming job search, honesty is important for job seekers to meet the demands of the quality and the integrity of employers for the peaceful life of college students, which require college students to do the specification of integrity practitioners. At present, the credit of college students is more likely to cause social trust crisis. The society regards the university student as the high quality group, gives the maximu m trust and concern. But because the distrust caused by honest and trustworthy problems between the members of society, the social trust degree decreased, which significantly reduces the quantity, in terms of quality and it also declines substantially, which will make the trust crisis increase until the social sy stem collapse.

\section{Status qua of college students credit deficiency}

Cheating in exams. At present, cheating in examinations has become an important problem for college students' loss of honesty and credit, has been common topic of college studen ts ignorant, then for his personal achievement demand will directly lead to college students to pull down the civilization veil to violate moral, cheating in the exam.

Malicious arrears tuition. At present college students with problems in colleges have become a hot potato. On the one hand, the reform of education, the state provides for the students to implement the payment to school; on the other hand, the state also stressed that a college student cannot afford to pay tuition fees and drop out of school. Schools in the face of a large number of rural students and many parents for students of urban laid-off workers, not easy to find out who is the most difficult, deliberate arrears caused an opportunity. Numerou graduates are not repayment, so that some schools have to open up the certificate warehouse. Such a situation in the long-term, and will give the school running. Bank lending, but the credibility of the whole society has a bad effect.

Refused to return national student loans. The national student loan is designed to help poor students finish their studies and make more talents for the country.. However, this multi benefit is facing the embarrassment of the school to be concemed about, the bank is worried about the public. This is mainly because many needy college students find jobs after the loan thing pretexts, write clearly.

False resume. Part of the graduate in order to cause employers to pay more and more attention to in a number of candidates, resorted to every means to make their own material brilliant, perfect, even exaggerated. Such as forged course grades and English and computer grade examination certificate; fiction during the period of school office; invent social practice experience; take the method of "substitution" suddenly, become "Miyoshi students," and "outstanding student cadres."

\section{Reasons for the lack of honesty of College Students}

Social factors -- the influence of social bad mood. In today's society did much of the credit deficiency phenomenon: the market is flooded with fake and shoddy goods; government officials of corruption are common; securities fraud agency public amassed a fortune; cultural market piracy filed one after another, despite repeated prohibition. These are to young college students brought negative influence, so that their original value view and world view impacted and even began to shake, the breeding ground for an opportunistic attempt to bad behavior. The imperfect of credit penalty mechanismand the imperfection of social credit evaluation system cannot get the sanction objectively, and encourage the students to be indifferent and honest. 
Family Factor - week family education. In the real society, the problem is that parents only care about the children's academic performance in daily life, but neglect the moral quality guidance. There is a number of parents who are regardless of the students, despite the children's spontaneous development, sometimes even bring the wrong ideas home, which is a negative impact on children. Some parents do not trust. On the surface of the actual highfalutin, resort to deceit. The education of children, to tell the truth, but a story, the children "and I do not know this is dead". These are bad for students' integrity and quality.

School factor - restriction mechanis m shortage. The moral education of many schools is light practice, and weight upgrade with out life basis which is too closed, There is no direction of real life, which is lack of openness. Some schools emphasis too much on "social standard" and ignore the ethical education which leads to a lack of moral education function and market generalization, moral and scientific, to test the separation, which has negative impact on the integrity of the students education.

The factor of college students themselves - lack of self cultivation. Most of the students in consciousness can clearly distinguish right from wrong and know what to do and what should not do. They understand the positive and correct, and in the pursuit of the inherent character of self perfection, but their self-control ability is relatively low and are lack of standards of the consciousness of their own behaviors. Because of the misleading of wrong moral concepts and wrong appearance of the society, students often cannot grasp themselves well, they show the behavior pattern which runs counter to the good faith.

\section{Countermeasures for college students honesty reconstruction}

To strengthen the reconstruction of college students honesty is not only an urgent task for colleges and universities but also for the whole society. The practice shows that the reconstruction of honesty is not only depending on which department can complete, it is a systematic project which needs the common effort and cooperation of the society, schools and families.

Creating atmosphere is the precondition of honesty reconstruction. Education is under the social environment. Environment is not consistent with the goal of education, education is weak. Therefore, to create a govemment stresses integrity, public credibility, and everyone to talk about the integrity of the social environment are very important. Firstly, to raise awareness. Thought is the forerunner of action, first of all, the whole society should realize the important meaning of hon esty. To fully understand the integrity is the basis to ensure the students to grow up healthily, is the inherent requirement of the development of the socialist market economy, is the important content of socialist moral construction, so as to reconstruct trust placed on the agenda, earnestly do a good job. Secondly, to increase the intensity of publicity plays a role in the public opinion and the full perspective of the publicity of the concept of in teg rity. The society should vigo ously carry forward the trad itional virtues of the Chinese nation, publicize and implement the implementation of the moral civil construction platform, so that the integrity of the concept rooted. Thirdly, the standard government behaviors of the government and the government play the leading role in the credit reconstruction.

Strengthen education is the focus of honesty and reconstruction. Family education and school education are complementary, both of which are indispensable. From the perspective of family education: firstly, parents should strive to improve their quality. Good faith set an example. Secondly, the intellectual is put in the primary position, gradually grasp the children's schooling quality. From the school education, attention should be paid to the proper position of honesty education in school education. To change the phenomenon that only focusing on wisdombut ignoring practice, the honesty education in school moral education system should be implemented in all aspects of the school education, from entrance education to graduate education, from moral education to basic courses, professional courses, from daily behavior management to various campus activities, as well as sincere letter, in order to make the good faith be consciousness penetrated into all aspects, penetrated into 
every comer. Secondly, to strengthen the management. To strengthen the management of teachers. In the school philosophy, to adhere to the principles of good faith, the right to exclude (money) to learn the interference of teaching work.

Perfect mechanisms are the guarantee of honesty and reconstruction. The problem of an institution is a question of "more fundamental, global, stable and long-term". Therefore, the integrity of the reconstruction does not only pay attention to education, foster good faith concept, but more importantly, to establish a comprehensive system of dishonesty, guidance, supervision, restraint and sanction s. Construction of good faith mechanism mainly includes the establishment of the basic law of the credit system and the system, the management of the credit intermediary organizations, and the formulation of the punishment method for the fraud. From the point of view of society, many places start to explore the credit evaluation system and the dishonesty punishment mechanism. As a galaxy of talents of active thinking, universities have the necessary to establish the mechanism of honesty education. There are a lot of universities such as Shanghai University, have established the basic domestic college credit file. Tianjin Normal University has launched the students credit evaluation system, and so on. Students credit evaluation system mainly include the following several contents: student credit files and credit archives faithfully record the student in the school during the study, work and life, including the student's basic situation, conduct, academic achievement, credit records, rewards and punishments, such as the implementation of electronic management, graduate students, credit files following Student Personnel files and submit to the employer, student's credit record extends to the society. In addition, the integrity assessment mechanism should also be paid attention to Records of quantitative and qualitative evaluation on College Students' honesty condition, according to the assessment of the situation in a timely manner to carry out a variety of educational activities, the implementation of measures of honesty education in time and space is more targeted, more reasonable. Thirdly, the integrity of rewards and punishment mechanism includes the integrity of the state and the party, the combination of awards, restrictions on loans, evaluation of dishonest behavior.

\section{Conclusions}

Honesty is the traditional virtue of Chinese culsture, and it is the eternal subject that college students pursue. It is an urgent and important job for students to develop honesty and trustworthin ess, to carry out the honesty education for college students, to construct the honesty education system for college studen ts and to improve the hon esty and credit quality of college students. There is no letter, no man without letter, no country, no country. Contemporary college students should be honest and trustworthy, ambitious, broad-minded, on the broad stage of reform and opening up and the modernization, giving full play to the own ingenuity, demonstrate the value of their life, and strive to create a worthy of the era and the people's performance.

\section{References}

[1] Chunbo Gao. The empirical analysis of the lack of College Students' academic integrity and the countermeasures. "Pursuing studies research", 2013.

[2] Yanhua Liu, Binyang Liu. The reasons and countermeasures of the lack of academic credibility education in colleges and universities. "Business", 2014.

[3] Liang Zhang. The reasons and countermeasures of the lack of academic integrity for college students. Journal of Hen an Institute of Science and Technology: Social Science Edition, 2015.

[4] Yuping Niu, Xue Wang. The reasons and countermeasures of the lack of academic integrity of postgraduates. Journal of Shenyang Agricultural Uinversity: Social Science Edition, 2014.

[5] Xichun Xu, Yan Fu. The research on the lack of academic honesty education for college students and the countermeasures. "Journal of College Counselors", 2013. 
[6] Weihong Yang. The cause and countermeasure of the lack of hon esty in college students during the period of social transformation. Human resource management: Academic Edition, 2009.

[7] Qiang Liu. Research on College Students' academic dishonesty and countermeasures. Shihezi University, 2010.

[8] Xiaomei Huang. The research on the problem of college students credit absence and the education countermeasures. Hubei University, 2010 -.

[9] Yuanjing Xiong. Research on honesty education for college students. Industrial and Commercial University of Chongqing, 2012. 